\title{
FORMATION OF WELL-DEFINED SOLUBLE AGGREGATES UPON FUSION TO MBP IS A GENERIC PROPERTY OF E6 PROTEINS FROM VARIOUS HUMAN PAPILLOMAVIRUS SPECIES.
}

Katia Zanier(1), Yves Nominé(1), Sebastian Charbonnier(1), Chris tine Ruhlmann(2), Patrick Schultz(2), Johannes Schweizer(3) and Gilles Travé(1)*

(1) Ecole Supérieure de Biotechnologie de Strasbourg, Institut Gilbert Laustriat (UMR 7175

LC1), Boulevard Sébastien Brant, BP 10413, 67412 Illkirch, France.

(2) Institut de Génétique et de Biologie Molécu laire et Cellulaire, CNRS/INSERM/ULP, 1 rue Laurent Fries, BP 163, 67404 Illkirch, France

(3) Arbor Vita Corporation, 772 Lucerne Drive, Sunnyvale, CA 94085, USA

* To whom correspondence should be addressed.

E-mail: trave@,esbs.u-strasbg.fr

Tel.: +33-3-90244720

Fax.: +33-3-90244718 


\section{ABSTRACT.}

Protein aggregation is a main barrier hindering structural and functional studies of a number of interesting biological targets. The E6 oncoprotein of Human Papillomavirus strain $16\left(\right.$ E6 $\left._{16}\right)$ is difficult to express under a native soluble form in bacteria. Produced as an unfused sequence, it forms inclusion bodies. Fused to the C-terminus of MBP, it is mainly produced in the form of soluble high molecular weight aggregates. Here we produced as MBP-fusions seven E6 proteins from other HPV strains $(5,11,18,33,45,52,58)$ belonging to four different species, and we compared their aggregation state to that of MBP-E6 ${ }_{16}$. Using a fast mutagenesis method, we changed most non-conserved cysteines to the isosteric residue serine in order to minimize disulfide bridge-mediated aggregation during purification. Static and dynamic light scattering measurements, ultracentrifugation and electron microscopy demonstrated the presence in all MBP-E6 preparations of soluble high-molecular weight aggregates with a well-defined spherical shape. These aggregated particles are relatively monodisperse but their amount and their size vary depending on the conditions of expression and the strain considered. For all strains, minimal aggregate formation occurs when the expression is performed at $15{ }^{\circ} \mathrm{C}$. Such observations suggest that the assembly of MBP-E6 aggregates takes place in vivo during protein biosynthesis, rather than occurring during purification. Finally, we show that all MBP-E6 preparations contain two zinc ions per protein monomer, suggesting that E6 domains within the high molecular weight aggregates possess a native-like fold, which enables correct coordination to the metal center.

Keywords: HPV, oncoprotein, E6, fusion protein, protein aggregation, protein overexpression, rapid mutagenesis, light scattering, soluble inclusion bodies. 
Abbreviations used: HPV, Human Papillomavirus; MBP, maltose binding protein; SLS, static light scattering; DLS, dyn amic light scattering; TEV, tobacco etch virus. 


\section{INTRODUCTION}

Human papillomaviruses (HPV) are small DNA viruses that infect epithelial tissues. 26 HPV species have been identified, comprising nearly 100 strains [1]. HPVs display distinct tropisms for different body sites (skin, mouth and genitalia) as well as distinct levels of pathogenicity. Infections by "low-risk" HPVs generate benign proliferative lesions whereas infections by "high-risk" HPVs can progress into cancer. Cervical carcinomas are one of the main causes of cancer-related death for women and are caused by infection of high-risk genital HPVs [2]. HPV 16 is the most common high-risk genital type responsible for $50 \%$ of the cervical cancers, followed by HPV 18 covering 14\% of the cancers [3]. Other oncogenic genital types include HPV 45, 31, 33, 52 and 58. The high-risk cutaneous HPV types 5 and 8 have been instead associated to the occurence of squamous cutaneous carcinoma (SCC) on sun-exposed areas of the skin of patients suffering from the rare genetic disease epidermodysplasia verruciformis (EV) [4].

HPV tumorogenesis is supported by the activities of two oncoproteins, E6 and E7. E6 proteins from high-risk genital HPVs form a trimeric complex with the tumor suppressor p53 [5] and the ubiquitin ligase E6-associated protein (E6AP) [6], which leads to ubiquitinmediated degradation of p53. High-risk genital HPV E6 also target many other cellular proteins to degradation (reviewed in [7]), including the MAGI family of proteins [8,9], which recognise E6 via their multiple PDZ domains. In contrast, little is known about the targets of the high-risk cutaneous HPV E6 proteins, which might carry out their functions via alternative mechanisms. For instance, E6 from HPV 5 and 8 do not target p53 to degradation, but they promote the degradation of the Bak pro-apoptotic protein which is normally induced after UV irradiation of the skin [10]. 
HPV E6 are cysteine-rich small proteins of about 150 amino acids, which consist of two zinc-binding domains, E6-N and E6-C $[11,12]$. We recently solved the solution structure of the E6-C domain and proposed a model for the structure of the full-length protein [13]. Yet the high-resolution structure of the entire E6 protein remains to be solved. This is still hindered by difficulties in the recombinant production of full-length E6 under a native and soluble form. Attempts to produce the native full-length protein in E. coli have mainly focussed on E6 from HPV 16 (E6 $\left.6_{16}\right)$ [11,14-16]. Most of these studies report on the aggregative tendencies of E6. We found that MBP-E6 ${ }_{16}$ fusions self-as semble during bacterial expression into high molecular weight particles ("soluble inclusion bodies") $[15,17]$. The resulting particles are prevented from precipitation by the highly soluble MBP. When the E6 protein is separated from the MBP moiety via linker proteolysis, it immediately precipitates. We also found that the aggregates, most probably formed in the cells upon overexpression, further increased during purification due to disulfide bridging promoted by the numerous cysteine residues found in E6 $6_{16}$ sequence. This second cause of aggregation could be eliminated by mutating six non-conserved cysteines of $\mathrm{E} 6_{16}$ to the isosteric residue serine $[15]$

In the present work we express as MBP fusions several E6 proteins of other HPV types, including major high-risk genital HPV 18, 33, 45, 52, 58, low-risk genital HPV 11 and high-risk cutaneous HPV 5. A fast mutagenesis approach is used to mutate non-conserved cysteines to serines. The influence of E6 sequence and expression temperature on the formation of soluble MBP-fused aggregates are investigated. Finally, p53 degradation and zinc binding by the MBP-E6 proteins are also characterised.

\section{MATERIALS AND METHODS}


A strategy for rapid multiple mutagenesis of E6 proteins. In order to rapidly mutate several E6 proteins at multiple positions, we applied an efficient PCR-based strategy, which was first proposed by Tomic et al. [18]. This strategy consists of performing PCR amplifications with primers containing the desired mutations, together with a site for a class II restriction enzyme placed at their 5' ends (Fig.1). Class II restriction enzymes recognize nonpalindromic sequences and cleave the DNA on a single site situated at a short distance from their recognition sequence in the $3^{\prime}$ direction. We used here the enzyme BsaI which cleaves at $\mathrm{N}+1$ at the 3 '-end and $\mathrm{N}+5$ at the 5 '-end following the last base of its recognition site. We also routinely use two other enzymes, BsmBI and BbsI, which respectively cleave at $\mathrm{N}+1$ (3'-end) and $\mathrm{N}+5$ ( $5^{\prime}$-end), and at $\mathrm{N}+2$ ( $3^{\prime}$-end) and $\mathrm{N}+6$ (5'-end), following the last base pair of their recognition sites. A PCR fragment generated using primers containing at their $5^{\prime}$ end a restriction site for any of these enzymes will present after cutting two sticky ends with 4-base 5 ' overhangs. Since these enzymes do not cut on their own restriction sites, these sticky ends can adopt any sequence, which can be chosen upon primer design. The restriction sites, situated at the extreme ends of the PCR fragments, are eliminated during purification of the cut PCR fragments. It is therefore possible to engineer, on two distinct PCR fragments, sticky ends which are self-compatible and will either perfectly retain the original sequence or introduce any planned mutation. Alternatively, the primers can also be designed so that the generated sticky ends will be compatible with the sites of classical restriction enzymes such as EcoRI, HindIII, BamHI, NcoI or Acc65I.

We generally apply the following rules:

1) The engineered four-base cohesive site should ideally contain three (G,C) to facilitate ligation.

2) The engineered cohesive site should not be self-complementary. 
3) The sequence of these four bases should be distinct for each end of all fragments which are going to be cloned together in the vector in order to avoid polymerisation or improper arrangement of the fragments. By taking this precaution we have succesfully ligated together up to six mutated fragments of the cDNA of HPV16 E6 in to the open expression vector.

4) After design of the oligomers one should always check that a new site for the classII en zyme has not been introduced.

5) The PCR amplification reactions should use a standard (therefore cheap) Taq polymerase with a large amount of template (200 $\mathrm{ng}$ of plasmid per $50 \mu 1$ reaction) and a small number of amplification cycles (12 cycles). Such conditions generate reproducibly large amounts of product with very little chance of PCR-induced mutations.

6) After ligation, the selection of clones should be made based on their capability to overexpress a protein at the expected size. It is normally sufficient to check three-four clones. However more clones may have to be screened if the multiple ligation step involves many fragments. Once this initial screening is performed, one or two clones expressing the protein at the right size can be sent for DNA sequencing. So far we did not have the case that a protein expressed at the right size would not present the exact expected sequence (we have already used this strategy for generating more than 100 point mutations in different proteins).

To illustrate the details of primer design, we describe in Fig. 2 the sequences of the primers which have been used for mutating four non conserved cysteines (C17, C66, C112 and C144) of HPV 11 E6.

PCR reaction, fragment processing and ligation into the expression vector. cDNA templates coding for HPV sequences were kindly provided by Prof. G. Orth (Institute Pasteur, Paris). The PCRs were performed in $50 \mu \mathrm{l}$ reaction mixes using RedTaq DNA Polymerase (Sigma-Aldrich) (standard enzyme and buffer conditions) with concentrations of $50 \mu \mathrm{M}$ of 
each nucleotide, $2 \mu \mathrm{M}$ of each primer and $200 \mathrm{ng}$ of plasmid bearing the template cDNA. The PCR program comprised a starting 2 min. denaturation cycle at $95{ }^{\circ} \mathrm{C}$ followed by 12 cycles with the following steps: denaturation $94{ }^{\circ} \mathrm{C}$ for $20 \mathrm{sec}$, annealing $60^{\circ} \mathrm{C}$ for $30 \mathrm{sec}$, elongation $72{ }^{\circ} \mathrm{C}$ for $50 \mathrm{sec}$, followed by a single final 8 -min step at $72{ }^{\circ} \mathrm{C}$ to complete elongation. The PCR products were separated on $2 \%$ agarose gel, purified and subsequently digested by BsaI (New England Biolabs, Ipswich, MA). Digests were separated on $2 \%$ agarose gel and purified. Series of digests allowing to reconstitu te the entire cDNA of each mutant E6 were ligated together into the expression vector PET-M 41 (kindly provided by Gunter Stier, EMBL, Heidelberg). This PET-derived vector allows to express the protein of interest as a fusion to the C-terminus of his-tagged Maltose Binding Protein (MBP) with a linker sensitive to TEV protease. Ligations were transfected in DH5 $\alpha$ bacteria. Four clones per construct were amplified, subjected to DNA minipreparation, transfected into BL21 DE3 and subjected to an expression test to verify the presence and correct size of the expected fusion protein. For each construct, one clone expressing the protein at the expected size was sent for DNA sequencing.

Expression and purification of E6 proteins. MBP-E6 samples were over-expressed using different conditions of temperature and duration of induction. E. Coli BL21 DE3 cultures were induced respectively at $37^{\circ} \mathrm{C}$ for 3 hours, at $27^{\circ} \mathrm{C}$ for 5 hours, at $15{ }^{\circ} \mathrm{C}$ for 17 hours and at $8{ }^{\circ} \mathrm{C}$ for 2 days. MBP-E6 samples used in light scattering experiments were purified from small-scale bacterial cultures of $50 \mathrm{ml}$. For all other experiments, MBP-E6 samples were produced from cultures of $500 \mathrm{ml}$. Buffer A $(50 \mathrm{mM}$ Tris $\mathrm{pH} 6.8,400 \mathrm{mM}$ $\mathrm{NaCl}$ and $2 \mathrm{mM} \mathrm{DTT}$ ) was used throughout the purification. Proteins were purified using amylose affinity chromatography according to already described protocols [19]. 
Static light scattering and fluorescence measurements. These experiments were performed using a SPEX Fluorolog-2 spectrofluorometer (SPEX Industies, Inc. Edison, NJ) whose characteristics have been previously described [17]. Protein samples were maintained at $20{ }^{\circ} \mathrm{C}$ in a thermostated cuvette holder during the measurements.

In our previous studies, we have described an "aggregation ratio" parameter (Ragg), which allows to estimate the degree of aggregation of MBP-fused protein samples. This parameter is expressed as the ratio of the intensities of scattered light at $280 \mathrm{~nm}\left(\mathrm{I}_{280}\right)$ and tryptophan fluorescence at $340 \mathrm{~nm}\left(\mathrm{I}_{340}\right)$. Here we have modified the assay described in $[15,17]$ and measured tryptophan fluorescence in denaturing conditions (7 M urea). This enables standardization of the fluorescence signal in a manner that it is not any more influenced by aggregation and/or folding. In addition, we have normalized the fluorescence values of the different E6 proteins according to the number of tryptophan residues. For static light scattering (SLS), protein samples were instead diluted in buffer A to concentrations equivalent to those employed in the fluorescence scans. Measurements were performed by setting both excitation and emission monochromators to $350 \mathrm{~nm}$ and allowing time-based recordings to proceed for $100 \mathrm{sec}$. Buffer contributions were measured and subtracted from scattering values. In summary, the Ragg parameters presented in this work are equal to the ratios of the intensities of scattered light at $350 \mathrm{~nm}$ and tryptophan fluorescence in denaturing conditions (i.e. $\left.\mathrm{I}_{350} / \mathrm{I}^{*}{ }_{340}\right)$.

Preliminary experiments have shown that Ragg ratios are concentration-independent between 0.2 and $2.0 \mu \mathrm{M}$. (data not shown). For this reason, all SLS measurements in this work were conducted at protein concentrations ranging between 0.3 and $1.5 \mu \mathrm{M}$.

Dynamic light scattering. Dynamic light scattering (DLS) was performed using a DynaPro $^{\mathrm{TM}}$ instrument (Protein Solutions ${ }^{\mathrm{TM}}$, Wyatt Technology Corporation). Protein 
preparations were adjusted to $5 \mu \mathrm{M}$ in buffer A. Sample temperature was maintained at $20^{\circ} \mathrm{C}$. During the measurements, the total scattering signal was maintained between 200 and 900 dpi by adjusting the instrument sensitivity to $10-20 \%$. Scattering data were analyzed using the Dynamics software (Protein Solutions ${ }^{\mathrm{TM}}$ ). The hydrodynamic radii reported in this work were obtained using the regularisation algorithm in Dynamics, which performs a multiple exponential fit of the raw data and provides a size distribution analysis for samples containing two or more populations. Interpretation using single and double exponential mono- and bimodal models in Dynamics were performed to further corroborate the findings of the regularis ation algorithm.

Ultracentrifugation. The sedimentation velocity $v$ of a spherical particle of radius $r$ is proportional to the sedimentation constant $s$, the distance $x$ from the center of rotation and the angular frequency $\omega$ :

$$
\begin{aligned}
& v=s \omega^{2} x \\
& \text { where } \quad s=\frac{M\left(1-\bar{V}_{2} \rho\right)}{N_{0} f}
\end{aligned}
$$

$f$ is described by the Stokes law [20] and is linearly dependent with $r ; M$ is the molecular weight; $1-\bar{V}_{2} \rho$ is the resulting buoyancy term ; $N_{0}$ is the Avogadro's number.

According to this relation, monomeric MBP-E6 (MW $=60 \mathrm{kDa})$ subject to a force of $110,000 \mathrm{x}$ g has a sedimenentation velocity $v$ of approximately $0.16 \mathrm{~cm} /$ hour when situated in the middle of the centrifuge tube (i.e. at a distance $x=8 \mathrm{~cm}$ from the centre of rotation). On the other hand, a particle consisting of $10 \mathrm{MBP}-\mathrm{E} 6$ units $(\mathrm{MW}=600 \mathrm{kDa})$ in the same conditions will travel at approximately $0.5 \mathrm{~cm} /$ hour. However, the sedimentation velocity is counterbalanced by the diffusion, which in the case of a monomeric MBP-E6 particle at $4{ }^{\circ} \mathrm{C}$ in water is around $0.1 \mathrm{~cm} /$ hour. 
Therefore, in order to separate the fraction of non-aggregated MBP-E6 from soluble aggregates, we choose to subject MBP-E6 preparations to a 14-hour ultracentrifugation at $110,000 \times \mathrm{g}$ (i.e. $36,000 \mathrm{rpm})$ at $4{ }^{\circ} \mathrm{C}$ in a swing rotor SW-41 (Beckman Coulter, Fullerton, CA).

Electron microscopy. MBP-E6 preparations were expressed at $15^{\circ} \mathrm{C}$ and affinitypurified. Samples were diluted to a final concentration of $30 \mathrm{ng} / \mu \mathrm{l}$ in buffer A. Five $\mu 1$ were deposited on an air glow-discharged carbon-coated grid. After 2 min adsorption samples were negatively stain ed with a $2 \%(\mathrm{w} / \mathrm{v})$ uranyl acetate solution. Images were acquired on a Philips CM120 transmission electron microscope equipped with a LaB6 filament and operating at $100 \mathrm{kV}$. Areas covered with individual molecules were recorded under low dose condition, at a magnification of $\mathrm{x} 45.000$ on a Pelletier-cooled CCD camera (Model 794, Gatan, Pleasanton, CA).

Determination of $\mathrm{Zn}^{2+}$ content (TSQ assay). $\mathrm{Zn}^{2+}$ concentrations in E6 samples were determined monitoring changes in fluorescence of the zinc selective fluorophore TSQ ( $(N-6-$ methoxy-8-quinolyl)-p-tolu enesulfonamide) (Molecular Probes, Eugene, OR). The protocols employed followed published procedures [16], with minor modifications. In brief, the protein bound zinc ions were ejected by incubating 2.5-5.0 $\mu \mathrm{M}$ of MBP-E6 with $0.6 \%$ of $\mathrm{H}_{2} \mathrm{O}_{2}$ in buffer $\mathrm{T}$ (10 mM sodium phosphate buffer, $\mathrm{pH} 7.0,10 \%$ glycerol) for two hours at room temperature. Hence, oxidized MBP-E6 samples were diluted 4-fold in TSQ buffer and $100 \mu 1$ aliquots mixed with equal volumes of buffer TS (10 mM sodium phosphate buffer, $\mathrm{pH} 7.0$, $10 \%$ glycerol, $200 \mu \mathrm{M}$ TSQ). Immediately after, the fluorescence at $477 \mathrm{~nm}$ (excitation wavelength $346 \mathrm{~nm}$ ) was measured. The background fluorescence of the unligand ed TSQ dye was measured and subtracted from the values obtained for the MBP-E6 samples. The zinc 
concentrations were calculated relative to $\mathrm{ZnSO}_{4}$ standards covering the concentration range between $0.2-4.0 \mu \mathrm{M}$. Protein concentrations were determined by denaturing protein samples in $7 \mathrm{M}$ urea and measuring absorbance at $280 \mathrm{~nm}$. The 8 tryptophan residues of MBP contribute to most of the absorption signal. However, depending on the HPV strain considered, E6 proteins contain 0 to 2 tryptophans. Extinction coefficients were calculated by adding the contributions of tyrosine and tryptophan residues present in the sequence of the different MBP-E6 constructs.

p53 degradation assays. p53 proteins were synthesized in vitro using the TNT T7/SP6 reticulocyte lysate transcription/translation system (Promega) as previously described [21]. p53 degradation was carried out by incubating $4 \mu 1$ of p53 translation product with $0.4 \mu \mathrm{M}$ MBP-E6 proteins in $25 \mathrm{mM}$ Tris- $\mathrm{HCl} \mathrm{pH} 7.5,100 \mathrm{mM} \mathrm{NaCl}$ and $2 \mathrm{mM}$ DTT at $29^{\circ} \mathrm{C}$ for 3 hours (total reaction volume $5 \mu \mathrm{l}$ ). Control reactions were made by replacing the MBP-E6 proteins with equivalent volumes of Buffer $A$. Reactions were stopped by adding $5 \mu 1$ of $2 \mathrm{x}$ SDS-loading buffer and analyzed by SDS-PAGE (12\% acrylamide). Gels were dried on Whatman 3M paper and analyzed by autoradiography.

\section{RESULTS}

Subcloning and fast cysteine/serine mutagenesis of a panel of HPV E6 proteins for expression as MBP-fusions. We cloned a panel of E6 proteins from various HPV strains (5, $11,16,18,33,45,52,58)$ for bacterial expression as fusions to the C-terminus of MBP. All HPV E6 proteins contain eight strictly conserved cysteines that are required for zinc-binding. In addition, an unusually high proportion of cysteines, which are not conserved, are interspaced at various positions in the sequences of E6 proteins. To minimize the risk of 
protein aggregation deriving from disulfide cross-brid ging we mutated to serines most of nonconserved cysteines in the E6 proteins investigated in this work. Given the high number of cysteine/serine mutations required for each protein we used a strategy which merges the steps of sub-cloning and of mutagenesis [18]. This strategy consists of generating PCR fragments containing the required mutations, which carry at their ends restriction sites for class II enzymes. These sites are positioned so that the digested PCR products present cohesive ends that enable their multiple ligation into the expression vector, therefore leading to a perfectly reconstituted cDNA containing all the planned mutations. The principle of this approach is illustrated in Fig. 1 and 2 and the details are fully described in Materials and Methods. The aligned sequences of the E6 proteins sub-cloned and the sites of cysteine/serine mutagen esis are reported in Fig. 3.

Effects of induction temperature on MBP-E6 16 soluble aggregation as monitored by light scattering measurements. Lower induction temperatures are thought to improve folding by slowing down over-expression in the bacterial cell and consequently to minimize aggregation events deriving from protein misfolding. In a previous study we have observed a decrease of the aggregation levels of MBP-E6 ${ }_{16}$ when expression temperature was decreased from $37{ }^{\circ} \mathrm{C}$ to $27{ }^{\circ} \mathrm{C}[15]$. Here we further investigate the effects of lower temperatures. Small-scale $(25-50 \mathrm{ml})$ bacterial cultures of MBP-E6 ${ }_{16}$ were induced at $37^{\circ} \mathrm{C}$ for 3 hours, at $27{ }^{\circ} \mathrm{C}$ for 5 hours, at $15^{\circ} \mathrm{C}$ for 17 hours and at $8{ }^{\circ} \mathrm{C}$ for 2 days. Similar expression levels were obtained at all conditions (data not shown). Protein preparations were obtained by amylose affinity-chromato graphy. We previously introduced an "aggregation ratio" parameter (Ragg) which consists of the ratio between the intensities of scattered light and tryptophan fluorescence both measured in a spectrofluorometer [15]. In the present work we slightly modified this assay. We have performed fluorescence measurements in denaturing conditions, 
so that these measurements, which quantify protein concentrations in solution, are no more influenced by folding and/or aggregation (see Materials and Methods). Dramatic differences in static light scattering by MBP-E6 16 produced at the various temperatures are observed. Maximal and minimal Ragg values are seen for the proteins expressed at, respectively, $37^{\circ} \mathrm{C}$ and $15^{\circ} \mathrm{C}($ Fig. $4 \mathrm{~A})$. Yet even the lowest light scattering value measured $(\mathrm{Ragg}=0.5)$ indicates the presence of soluble aggregates. By comparison, a monodisperse solution of monomeric MBP displays a Ragg value of $\sim 0.002$ (data not shown).

MBP-E6 16 preparations were also analyzed by dynamic light scattering (DLS). DLS data were acquired on the same samples and on the same day as the SLS measurements. Sample concentration was adjusted to $5 \mu \mathrm{M}$. Hydrodynamic radii were derived from the scattering data assuming a spherical model as described in Materials and Methods. Hydrodynamic radii of the aggregated MBP-E6 samples vary from 28 to $10 \mathrm{~nm}$ corresponding to molecular weights of respectively 8000 to $750 \mathrm{kDa}$, according to the calibration curve provided by the program used for data analysis (see Materials and Methods). This, in turn, corresponds to particles consisting of approximately 130 and 12 MBP-E6 monomer units. In agreement with previous DLS data on MBP-E6 ${ }_{16}$ [17] the polydispersity values reported in Fig. 4B are rather low (approximately 30\% of the hydrodynamic radius) indicating that multimeric assemblies of MBP-E6 $6_{16}$ are fairly homogeneous in size. The DLS data show the same general trend as the SLS results, with the maximal and minimal average aggregate sizes being observed for the samples expressed at $37^{\circ} \mathrm{C}$ and $15^{\circ} \mathrm{C}$ respectively (Fig. 4B).

Light scattering analysis of the aggregation properties of HPV E6 proteins. We therefore proceeded to investigate the aggregation properties of other E6 proteins, including those from HPV strains 5, 11, 16, 18, 33, 45, 52 and 58. In order to study the specific effects of induction temperature on the different MBP-E6 proteins, we compared MBP-E6 
preparations obtained at $27^{\circ} \mathrm{C}$ and $15^{\circ} \mathrm{C}$. Samples were purified as described in the previous paragraph and analyzed by SLS immediately followed by DLS measurements.

Interestingly, lowering of induction temperature significantly reduces Ragg parameters (by approximately 2-fold) only for some of the E6 proteins, including those from HPV 5, 16, 52 and 58. In contrast, Ragg parameters from other E6 proteins, such as 11, 18, 33, 45, do not vary considerably within th is temperature range (Fig. $5 \mathrm{~A}$ ). MBP-E6 ${ }_{16}$ preparations display the lowest scattering values, with an average Ragg of 0.5. Intermediate Ragg values, between 1 and 1.25, are found for $\mathrm{E} 6_{11}$ and $\mathrm{E}_{18}$ and E6 $6_{33}$ preparations. The highest Ragg values, between 1.5 and 2.0, are instead found for samples of $\mathrm{E} 6_{5}, \mathrm{E} 6_{33}, \mathrm{E} 6_{45}$ and $\mathrm{E} 6_{52}$ and $\mathrm{E} 6_{58}$ (Fig. 5A). Overall, over-expression at $15{ }^{\circ} \mathrm{C}$ leads to Ragg values ranging between 0.5 and 2.0 for all E6 proteins analyzed. This indicates that all these preparations contain soluble MBP-E6 aggregates.

Interestingly, changes in Ragg values of MBP-E6 preparations analyzed by SLS (Fig. 4A) do not always correlate with changes in particle size analyzed by DLS (Fig. 4B). The marked decrease in particle size occurring for HPV 16 E6 upon reduction of induction temperature is only observed for variants 11 and 45 . These E6 variants do not, on the other hand, display strong temperature-dependent variations in their Ragg values such as those observed for HPV16 E6. Overall, the hydrodynamic radii of soluble aggregates in MBP-E6 preparations obtained at $15{ }^{\circ} \mathrm{C}$ vary between 9 and $17 \mathrm{~nm}$ (corresponding to molecular weights of approximately 600 and $2500 \mathrm{kDa}$, respectively). Similarly to HPV 16 E6, low polyd ispersity values are observed for the other HPV E6 proteins, particularly for preparations expressed at $15{ }^{\circ} \mathrm{C}$ (between $15 \%$ and $30 \%$ of the av erage radius, see Fig. 5B).

Ultracentrifugation quantifies the amounts of protein involved in agg regated particles within E6 preparations. We used ultracentrifugation to pellet MBP-E6 soluble aggregates and 
analyzed the protein recovered in the supernatant. We limited our analysis to samples overexpressed at $15{ }^{\circ} \mathrm{C}$. MBP-E6 preparations from the different HPV variants were affinity purified by amylose chromatography and their concentration adjusted to $12 \mu \mathrm{M}$. Samples were subject to a 14 -hour ultracentrifugation at $4{ }^{\circ} \mathrm{C}$ and $110,000 \mathrm{x}$ g in a swing rotor $\mathrm{SW}-41$ (Beckman). According to the calculations (see Materials and Methods) such centrifugation conditions, applied to a protein preparation diluted in a buffer presenting approximately the viscosity of water, are suitable for pelleting large molecular weight particles (above $600 \mathrm{kDa}$ ) whereas low molecular weight particles (150 kDa or below) should remain in the supernatant. After ultracentrifugation, pellets containing MBP-E6 protein were visible and supernatants displayed negligible light scattering, confirming clearance from MBP-E6 aggregates (data not shown). The percentages of recovery of MBP-E6 in the supernatants are reported in Fig. 6. The recovery varies for the different E6 variants analyzed, with E6 ${ }_{16}$ preparations displaying the largest fraction of non-aggregated protein (36\%). For E6 ${ }_{11}, \mathrm{E} 6_{18}$ and $\mathrm{E} 6_{33}$ preparations the percentages of recovery vary between 15 and 23\%. For E6 6 , E6 $45, \mathrm{E}_{52}$ and E6 68 preparations the recovery is instead below $10 \%$. Altogether, these results are in agreement with the Ragg parameters obtained from the SLS assay and confirm that variations in light scattering are associated with different levels of aggregation.

MBP-E6 preparations do not contain major amounts of GroEL chaperone. MBP-fusion proteins have often been reported to co-purify with GroEL $[22,23]$. This abundant bacterial chaperone consists of two heptameric rings of a single polypeptide unit of approximately 55 $\mathrm{kDa}$. We reasoned that the large soluble particles observed in MBP-E6 preparations might be the result of GroEl sequestering misfolded E6 moieties. The molecular weight of the GroEL polypeptide is close to that of MBP-E6 proteins $(\sim 60 \mathrm{kDa})$, thus preventing unambiguous detection of GroEL by SDS-PAGE. To investigate this possibility, we cleaved affinity- 
purified MBP-E6 preparations by TEV protease. In all MBP-E6 samples analyzed protease digestion proceeded mostly to completion, yielding two bands of respectively $\sim 40 \mathrm{kDa}$ (MBP) and $20 \mathrm{kDa}$ (E6) on a SDS gel. Residual bands at $60 \mathrm{kDa}$ detected in some of the preparations, which may be associated with incomplete protease digestion of MBP-E6 and/or possible GroEL contamination, account for less than $5 \%$ of the total protein in the sample (Fig. 7). Such findings rule out the possibility of a major GroEL contamination in the MBPE6 samples.

Soluble aggregates of MBP-E6 form defined spherical assemblies as observed in electron microscopy. We proceeded with the investigation of the structure of soluble MBP-E6 aggregates by direct electron microscopy observation. Affinity purified MBP-E6 16 preparations expressed at $15{ }^{\circ} \mathrm{C}$ were adjusted to a concentration of $30 \mathrm{ng} / \mu \mathrm{l}$, deposited on a carbon-coated grid and negatively stained using a uranyl acetate solution. Fig. 8 shows representative images from these preparations, which reveal the presence of remarkably homogenous particles with a well-defined spherical structure and diameters of $18 \mathrm{~nm} \pm 2 \mathrm{~nm}$. Likewise, spherical structures of similar size are observed in preparations of MBP-E6 11 expressed at $15^{\circ} \mathrm{C}$ (data not shown).

MBP-E6 soluble aggregates do not contain disulfide cross-bridges and possess nativelike zinc content. We analyzed MBP-E6 preparations containing soluble aggregates by SDSPAGE in the presence and in the absence of the reducing agent $\beta$-mercap toethanol. No bands could be detected at molecular weights higher than that of a single MBP-E6 polypeptide chain $(60 \mathrm{kDa})$ (data not shown). This indicates that soluble aggregates arise from processes other than chemical cross-linking. Therefore the Cys/Ser mutagenesis approach resulted in the complete suppression of cystein cross-brid ging during purification. 
Evidence from work on other zinc binding proteins, such as HPV 16 E7, has shown that loss of metal coordination can induce sample aggregation. We monitored the $\mathrm{Zn}^{2+} / \mathrm{E} 6$ stoichiometry on a selected set of MBP-E6 preparations (which includes E6 variants 11, 16 and 18), using the selective fluorophore TSQ. MPB-E6 proteins were expressed at $15{ }^{\circ} \mathrm{C}$, purified by amylose affinity chromatography and subjected to overnight ultracentrifugation in order to pellet soluble aggregates (see above). Samples were taken both before (indicated as $\mathrm{T}$ ) and after (indicated as S) ultracentrifugation and the $\mathrm{Zn}^{2+}$ concentrations measured by the TSQ assay. We found that both samples containing soluble aggregates (which account for 65$85 \%$ of total protein, see figure 6 ) and cleared preparations display a $\mathrm{Zn}^{2+} / \mathrm{E} 6$ stoichiometry close to 2:1 (Table I). Such finding is expected from the common architecture of HPV E6 proteins, all consisting of two zinc-binding domains. The data show that E6 self-assembly processes observed in this work are not related to loss of zinc ions.

p53 degradation activities of MBP-E6 preparations cleared from soluble aggregates. E6 proteins containing the Cys/Ser mutations were tested for $\mathrm{p} 53$ degradation activity. MBPE6 proteins from HPV strains $5,11,16,18,33,45,52$ and 58 were expressed at $15{ }^{\circ} \mathrm{C}$, affinity-purified and cleared from soluble aggregates by ultracentrifugation. MBP-E6 proteins were incubated with ${ }^{35} \mathrm{~S}$ labelled $\mathrm{p} 53$ at a constant concentration of $0.4 \mu \mathrm{M}$ for 3 hours at 29 ${ }^{\circ}$ C. Fig. 9 shows that all E6 variants from "high-risk" genital HPV strains degrade p53 (lanes 3-8), while the cutan eous E6 (lane 1) and the "low-risk" genital E6 11 (lane 2) do not seem to affect p53 levels. These data are fully consistent with the known activities of these various E6 proteins relative to $\mathrm{p} 53$.

\section{DISCUSSION}


When dealing with problematic proteins, MBP-induced solubilisation is often accompanied by the presence of large molecular weight aggregates [24-28]. Such multimeric structures can be purified from bacterial lysates using amylose-affinity chromatography. In our previous work we showed that aggregation of MBP-E6 16 originated from at least two distinct phenomena: formation of soluble large molecular weight particles, most probably taking place in vivo during protein expression, and intermolecular disulfide bridge crosslinking, occurring in vitro during extraction, purification and storage of the proteins [15]. The unusually high number of cysteines found in E6 sequences leads to intermolecular disulfide bridge formation even at mild oxidative conditions. In the present work, we have applied the same strategy that formerly allowed us to isolate stable monomeric E6 $6_{16}$ proteins [15], i.e., the mutagenes is of non-conserved cysteines into the isosteric residue serine. The introduction of multiple Cys/Ser mutations in each E6 construct seems to efficiently prevent disulfide bridge formation. On the other hand it does not appear to alter the protein's sequence and/or structural features required for wild-type activities, such as coordination to $\mathrm{Zn}^{2+}$ ions and p53 degradation. Here we demonstrate that $\mathrm{E} 6$ samples have a $\mathrm{Zn}^{2+}$ : protein stoichiometry of 2:1, which is predicted from the common architecture of all HPV E6 proteins. We also show that all high-risk genital E6 Cys/Ser mutants analyzed have retained their capability to degrade p53 in vitro. In addition, in a previous work [19] we have shown that some of these E6 mutants (including those from HPV strains 16, 18, 33 and 58) interact with an E6AP derived 18-peptide with affinities in the low micromolar range.

Elimination of oxidative cross-linking during purification has allowed us to proceed to the study of the properties of soluble MBP-E6 aggregates originating from in vivo selfassembly pathways. To carry out this task we have combined techniques, such as dynamic and static light scattering and ultracentrifugation, which provide complementary information on the amounts and sizes of large soluble aggregates in the preparations. DLS provides 
information on the size and dispersity of the soluble aggregated particles, while the SLS signal varies linearly with concentration and with the cube of the particle's radius. Ultracentrifugation, performed in the conditions indicated above, provides instead a quantitative estimate of the amounts of protein associated with a population of large molecular weight aggregates. It is to be noticed that other methods, less demanding in terms of instrumentation, have also been proposed to monitor the presence of aggregated particles in preparations of fusion proteins, such as sandwich ELISA [17], native gel analysis [29] and sucrose gradients ultracentrifugation [30]. A recent review published in [31] includes a comprehensive list of methods used to study protein aggregates.

A striking feature of MBP-E6 soluble multimeric as semblies is their remarkable size homo geneity, revealed by the low polydispersity of all preparations analyzed by DLS. Based on results from immunochemical assays, we previously proposed a micellar model, in which the E6 moieties are buried and hidden from the solvent, whereas MBP units are exposed to the solvent [17]. In the current study, the regular spherical shape observed by electron microscopy provides further support to the micellar model. When protein over-expression is carried out at $15^{\circ} \mathrm{C}$, MBP-E6 multimeric particles from the different HPV strains have similar average hydrodynamic radii. When expression temperature is raised to $27^{\circ} \mathrm{C}$, larger particle radii are observed for some, but not all, MBP-E6 proteins. This direct effect of the expression temperature on particle size further supports the view that the soluble MBP-E6 aggregates result from in vivo self-as sembly pathways.

We previously proposed that the E6 moieties are not properly folded within the soluble MBP-E6 aggregated particles [17]. This was supported by the fact that proteolysis of the linker separating MBP and E6 generated rapid formation of E6 precipitates which could only be solubilised using strong denaturing agents. On the other hand, we also observed a sharp cooperative transition upon chemical denaturation of MBP-E6 soluble aggregates, 
which may reflect the fact that E6 moieties within these structures interact via a network of identical molecular interfaces [17]. In the present work, we demonstrate that preparations including a large excess of soluble aggregates contain two zinc molecules for each MBP-E6 polypeptide chain. These findings indicate that the two zinc-binding domains of E6 moieties within soluble aggregates possess a native-like fold, which enables correct coordination to the metal center. These observations also suggest that the E6 self-assembly processes described in this work do not result from loss of zinc binding, a mechanism which has been describe to promote aggregation of a number of zinc binding proteins such as HPV E7 [32] and members of the RING finger family [33].

In the present work we show that eight E6 proteins of four phylogenetically distinct HPV species form large molecular weight aggregates with similar properties. Such finding suggests that soluble aggregation is a general behavior of MBP fused E6 proteins of most HPV species. The solution structure of HPV16 E6 C-terminal domain has shown that whereas the general fold of HPV E6 proteins seems to be extremely conserved, their surface properties appear extremely variable [13]. Here we observe that the levels of soluble aggregates vary among the E6 proteins analyzed, ranging between $64 \%$ of the total protein, in the case of MBP-E6 16 , and 93-94\%, for MBP-E6 5 and MBP-E6 45 . We therefore wondered whether surface properties such as hydrophobicity explain the different aggregation tendencies observed for these variants. It is generally accepted that surface hydrophobicity increases the propensity of a protein to aggregate by promoting local unfold ing events which destabilize the native three-dimensional structure $[34,35]$. We therefore examined the number of exposed hydrophobic residues (including Val, Leu, Ile, Trp, Phe, Met and Tyr) on the surface of the pseudo-dimeric model proposed in [13] for the different E6 proteins. As a result we found no straightforward correlation between surface properties and specific aggregation tendencies of each variant. For instance, E6 16 , which displays the lowest tendency to polymerize, has fewer 
exposed hydrophobic residues ( $10 \%$ of the total number of residues) than $\mathrm{E} 6_{5}(17 \%)$. On the other hand, E6 16 surface hydrophobicity is very similar to that of E6 45 (with $11 \%$ of hydrophobic exposed residues), which, similarly to $\mathrm{E}_{5}$, has a high tendency to form soluble aggregates. Hence, it appears that the phenomenon leading to the formation of the large MBPE6 aggregates may notbe driven by the surface properties of these proteins.

The work presented here provides evidence for structural organization within MBP-E6 soluble aggregates. It will be extremely in teresting to further analyse the structural features of the E6 moieties present in these aggregated particles. These studies may provide further understanding into the processes of protein over-expression, folding and aggregation during biosynthes is in the host cell.

\section{ACKNOWLEDGMENTS}

We are grateful to members of the Structural Biology laboratory at IGBMC (Strasbourg) for access and help with the light scattering equipment. We thank Prof. G. Orth (Institut Pasteur, Paris) for providing the plasmids containing the HPV genomes. K.Z. and S.C. are supported by a fellowship from the Fondation pour la Recherche Medicale (FRM) and Ligue Nationale Contre le Cancer. This work was funded by the following organizations: Arbor Vita Corporation (Sunnyvale, CA), Association pour la Recherche sur le Cancer (ARC), Institut National de la Santé et de la Recherche Médicale, Centre National pour la Recherche Scientifique (CNRS) and Université Louis Pasteur (Strasbourg). 


\section{FIGURE AND TABLE LEGENDS}

Table I Experimentally derived $\mathrm{Zn}^{2+}$ :protein stoichiometries for MBP-E6 samples from variants 11,16 and $18 . \mathrm{T}$ (total) and $\mathrm{S}$ (supernatant) indicate respectively samples taken before and after ultracentrifugation. Zinc concentrations are measured by the TSQ assay and calculated relative to $\mathrm{ZnSO}_{4}$ standards (see Materials and Methods). Protein concentrations are determined by denaturing protein samples in $7 \mathrm{M}$ urea and measuring absorbance at 280 $\mathrm{nm}$.

Fig.1. PCR-based multiple-point mutagenes is strategy using class II restriction enzymes. Here we show as an example the procedure we have followed for mutating into serines C17, C66, C112 and C144 of HPV 11 E6. Step (I): three PCR amplifications are performed using appropriate primers (see Fig. 2 for sequence details) bearing the planned mutations and BsaI restriction sites at their 5' extremities. The "-dir" primers are designed to match the coding strand whereas the "-rev" primers are designed to match the reverse (complementary) strand. Step (II): after digestion by BsaI, the fragments present the following characteristics: a NcoIcohesive site and the (engineered) cohesive site 1 (fragment A); the cohesive site 1 and the cohesive site 2 (fragment B); the cohesive site 2 and a Acc65I-cohesive site (fragment C). Step (III): the three fragments are ligated together into the open NcoI-Acc65I vector, reconstituting HPV 11 E6 cDNA bearing the four plann ed mutations.

Fig. 2 Sequence details of the primers used for multiple Cys/Ser mutagenesis of HPV11 E6. (A) The position of the six primers in the context of the aminoacid sequence of HPV 11 E6. For clarity the matching DNA sequences of the primers (boxed regions) are represented by the sequence of the amino-acids that they code for. The Cys/Ser point mutations introduced 
by the primers are indicated. The non-boxed extensions of the primers represent the nature and the order of the restriction sites (BsaI, NcoI, Acc65I) that they present at their 5'-ends. The "buffer" regions stand for a 6-base extension at the 5' extremity which is required for optimal binding of BsaI to its recognition site. (B) The DNA sequences of the six primers. Note that the "-rev" (reverse) primers are written in 3 '-5' orientation in order to respect the Nterminal to $\mathrm{C}$-terminal orientation of the protein sequences. The codons corresponding to the mutated residues are underlined. The sequences of the cohesive four-base 5'-overhangs generated upon BsaI digestion are shaded. Note the perfect complementarities of cohesive sites 1 of A-rev and B-dir and of cohesive sites 2 of B-rev and C-dir. Also note that the design implies that all the region situated at the 5 ' side of the shaded sequence will be lost after cutting of the PCR fragment.

Fig. 3 Sequence alignment of E6 proteins investigated in this work. HPV strain type is reported on the left hand side; $\mathrm{nt}$ and ct indicate respectively the $\mathrm{N}$-terminal and $\mathrm{C}$-terminal $\mathrm{Zn}^{2+}$ binding domains (E6-N and E6-C). The histogram indicates the percentage of side chain exposure to the solvent of the corresponding amino acid positions and it is derived from the structure of the E6-C domain [13]. Secondary structure elements of the E6-C domain are indicated. $\underline{\mathrm{C}}$ stands for conserved cysteines involved in $\mathrm{Zn}^{2+}$ coordination; $\mathrm{C}$ indicates nonconserved cysteines which have been replaced by serines in the constructs used in the present work.

Fig. 4 Influence of induction temperature on the formation of soluble aggregates of MBP-E6 as measured by Static (A) and Dynamic (B) Light Scattering (SLS and DLS). Expression temperatures are indicated. In order to show the reproducibility of the data, experiments are performed in duplicate, using two distinct protein preparations. (A) Ragg parameters as 
derived from SLS measurements. Ragg parameters are equal to $\mathrm{I}_{350} / \mathrm{I}^{*}{ }_{340}$, that is the intensity of the light scattered by the sample at $350 \mathrm{~nm}$ divided by the tryptophan fluorescence at 340 $\mathrm{nm}$ measured in denaturing conditions. Fluorescence values are normalized by the number of tryptophan residues of each MBP-E6 fusions. All measurements are performed at low protein concentrations, ranging between 0.3 and $1.5 \mu \mathrm{M}$. (B) Hydrodynamic radii obtained from DLS. Error bars represent size polydispersity and are derived from the half-maximal width of the Gaussian distribution of the radius measured. The expected radius for a monomeric 60 $\mathrm{kDa}$ MBP-E6 protein is $3.0 \mathrm{~nm}$. Sample concentrations were adjusted to $5 \mu \mathrm{M}$.

Fig. 5 Comparison of the aggregation properties of different E6 variant proteins. Ragg parameters (A) and hydrodynamic radii (B) are presented for the different MBP-E6 samples. HPV strain types are indicated. Grey and white histograms indicate MBP-E6 preparations over-expressed respectively at $27{ }^{\circ} \mathrm{C}$ and $15{ }^{\circ} \mathrm{C}$. Experiments are performed in duplicate, using two different protein preparations, to report on the reproducibility of the data. See also legend of Fig. 4.

Fig. 6 Partial field of a micro graph showing negatively stained MBP-E6 ${ }_{16}$ soluble aggregates. Spherical isolated particles are indicated (arrows). Bar $=50 \mathrm{~nm}$.

Fig. 7 Recovery of non-aggregated MBP-E6 from different variant preparations after ultracentrifugation. HPV strain types are indicated. MBP-E6 proteins are expressed at $15{ }^{\circ} \mathrm{C}$, affinity-purified and their concentration adjus ted to $12 \mu \mathrm{M}$. Subsequently, protein samples are subjected to 14-hour ultracentrifugation at 110,000 x g. For all MBP-E6 proteins, equal sample volumes are taken before ( $\mathrm{T}$, total) and after ultracen trifugation ( $\mathrm{S}$, supernatant) and loaded on a 12\% SDS gel (lanes 1-16). The percentages of MBP-E6 recovery after 
ultracentrifugation are calculated from protein concentrations measured by absorbance at 280 nm.

Fig. 8 TEV cleavage of affinity-purified MBP-E6 preparations containing soluble aggregates. Samples were taken before ( $T$, total) and after protease digestion ( $D$, digested) and loaded on lanes 1-6 of a $12 \%$ SDS-PAGE gel. HPV strain types are indicated. The migration of the molecular weight markers (in $\mathrm{kDa}$ ) is reported on the left hand side.

Fig. 9 p53 degradation in the presence of $0.4 \mu \mathrm{M}$ of MBP-E6 proteins, which are previously affinity-purified and separated from soluble aggregates by ultracentrifugation. HPV stain types of the MBP-E6 proteins are indicated (lanes 1-8). Lane 9: Control. 


\section{REFERENCES}

[1] de Villiers, E. M., Fauquet, C., Broker, T. R., Bernard, H. U. \& zur Hausen, H. Classification of papillomaviruses. Virology, 324 (2004), 17 - 27.

[2] zur Hausen, H. Papillomaviruses in human cancers. Proc Assoc Am Physicians, 111(6) (1999), 581-587.

[3] Bosch, F., Manos, M., Munoz, N., Sherman, M., Jansen, A., Peto, J., Schiffman, M., Moreno, V., Kurman, R. \& Shah, K. Prevalence of human papillomavirus in cervical cancer: a worldwide perspective. International biological study on cervical cancer (IBSCC) Study Group. J Natl Cancer Inst., 87 (1995), 796-802.

[4] Pfister, H. Chapter 8: Human papillomavirus and skin cancer. J Natl Cancer Inst Monogr., 31 (2003), 52-56.

[5] Werness, B. A., Levine, A. J. \& Howley, P. M. Association of human papillomavirus types 16 and 18 E6 proteins with p53. Science, 248 (1990), 76-79.

[6] Scheffner, M., Huibregtse, J. M., Vierstra, R. D. \& Howley, P. M. The HPV-16 E6 and E6-AP complex functions as a ubiquitin-protein ligase in the ubiquitination of p53. Cell, 75 (1993), 495-505.

[7] Chakrabarti, O. \& Krishna, S. Molecular in teractions of 'high risk' human papillomaviruses E6 and E7 oncoproteins: implications for tumour progression. $J$ Biosci., 28(3) (2003), 337-48.

[8] Glaunsinger, B., Lee, S., Thomas, M., Banks, L. \& Javier, R. Interactions of the PDZprotein MAGI-1 with adenovirus E4-ORF1 and high-risk papillomavirus E6 oncoproteins. Oncogene, 19(46) (2000), 5270-5280.

[9] Thomas, M., Laura, R., Hepner, K., Guccione, E., Sawyers, C., Lasky, L. \& Banks, L. Oncogenic human papillomavirus E6 proteins target the MAGI-2 and MAGI-3 proteins for degradation. Oncogene, 21 (2002), 5088-5096. 
[10] Jackson, S., Harwood, C., Thomas, M., Banks, L. \& Storey, A. Role of Bak in UVinduced apop tosis in skin cancer and abrogation by HPV E6 proteins. Genes Dev, 14(23) (2000), 3065-73.

[11] Lipari, F., McGibbon, G. A., Wardrop, E. \& Cordingley, M. G. Purification and biophysical characterization of a minimal functional domain and of an $\mathrm{N}$-terminal $\mathrm{Zn} 2+$-binding fragment from the human papillomavirus type 16 E6 protein.

Biochemistry, 40(5) (2001), 1196-204.

[12] Nominé, Y., Charbonnier, S., Ristriani, T., Stier, G., Masson, M., Cavusoglu, N., Van Dorsselaer, A., Weiss, E., Kieffer, B. \& Travé, G. Domain substructure of HPV E6 protein: biophysical characterization of E6 C-terminal DNA-binding domain. Biochemistry, 42 (2003), 4909-4917.

[13] Nomine, Y., Masson, M., Charbonnier, S., Zanier, K., Ristriani, T., Deryckere, F., Sibler, A. P., Desplancq, D., Atkinson, R. A., Weiss, E., Orfanoudakis, G., Kieffer, B. \& Trave, G. Structural and functional analysis of E6 oncoprotein: insights in the molecular pathways of human papillomavirus-mediated pathogenesis. Mol Cell, 21(5) (2006), 665-78.

[14] Daniels, P. R., Sanders, C. M., Coulson, P. \& Maitland, N. J. Molecular analysis of the interaction between HPV type $16 \mathrm{E} 6$ and human E6-associated protein. FEBS Letters, 416 (1997), 6-10.

[15] Nominé, Y., Ristriani, T., Laurent, C., Lefèvre, J. F., Weiss, E. \& Travé, G. A strategy for optimizing the monodispersity of fusion proteins: application to purification of recombinant HPV E6 oncoprotein. Protein Eng., 14(4) (2001), 297-305.

[16] Degenkolbe, R., Gilligan, P., Gupta, S. \& Bernard, H. U. Chelating agents stabilize the monomeric state of the zinc binding huma, papillomavirus 16 E6 oncoprotein. Biochemistry, 42 (2003), 38683873. 
[17] Nominé, Y., Ristriani, T., Laurent, C., Lefèvre, J. F., Weiss, E. \& Travé, G. Formation of soluble inclusion bodies by HPV E6 oncoprotein fused to Maltose-binding protein. Protein Expr Purif., 23(1) (2001), 22-32.

[18] Tomic, M., Sunjevaric, I., Savtchenko, E. S. \& Blumenberg, M. A rapid and simple method for introducing specific mutations into any position of DNA leaving all other positions unaltered. Nucleic Acids Res, 18(6) (1990), 1656.

[19] Zanier, K., Charbonnier, S., Baltzinger, M., Nomine, Y., Altschuh, D. \& Trave, G. Kinetic analysis of the interactions of Human Papillomavirus E6 oncoproteins with the ubiquitin ligase E6AP using Surface Plasmon Resonance. J. Mol. Biol., 349 (2005), 401-412.

[20] Cantor, C. R. \& Schimmel, P. R. (1998). Biophysical Chemistry, part II: techniques for the study of biological structure and function., Freeman and Company, New York.

[21] Ristriani, T., Nomine, Y., C, L., Weiss, E. \& Trave, G. Protein mutagen esis with monodisper sity-based quality probing: selective inactivation of p53 degradation and DNA-binding properties of HPV E6 oncoprotein. Protein Expr Purif., 26(3) (2002), 357-367.

[22] Bjorndal, B., Trave, G., Hageberg, I., Lillehaug, J. \& Raae, A. Expression and purification of receptor for activated C-kinase 1 (RACK1). Protein Expr Purif., 31 (2003), 47-55.

[23] Douette, P., Navet, R., Bouillenne, F., Brans, A., Sluse-Goffart, C., Matagne, A. \& Sluse, F. E. Secondary-structure characterization by far-UV CD of highly purified uncoupling protein 1 expressed in yeast. Biochem $J, \mathbf{3 8 0}(\mathrm{Pt} 1)$ (2004), 139-45.

[24] Louis, J. M., McDonald, R. A., Nasheed, N. T., Wondrak, E. M., Jerina, D. M., Oroszlan, S. \& Mora, P. T. Autoprocessing of the HIV-1 protease using purified wild- 
type and mutated fusion proteins expressed at high levels in Escherichia coli.

European Journal of Biochemistry, 199 (1991), 361-369.

[25] Saavedra-Alanis, V. M., Rysavy, P., Rosenberg, L. E. \& Kalousek, F. Rat liver mitochondrial processing peptidase: both $\alpha$-and $\beta$-subunits are required for activity. The Journal of Biological Chemistry, 269 (1994), 9284-9288.

[26] Lorenzo, H. K., Farber, D., Germain, V., Acuto, O. \& Alzari, P. M. The MBP fusion protein restores the activity of the first phosphatase domain of CD45. FEBS Letters, 411 (1997), 231-235.

[27] Sachdev, D. \& Chirgwin, J. M. Properties of soluble fu sions between mammalian aspartic proteases and bacterial maltose-binding protein. Journal of protein chemistry, 18 (1999), 127-136.

[28] Swalley, S., Baker, B., Calder, L., Harrison, S., Skehel, J. \& Wiley, D. Full-length influenza hemagglutinin HA2 refolds in to the trimeric low-pH-induced conformation. Biochemistry, 43 (2004), 5902-5911.

[29] Stegemann, J., Ventzki, R., Schrodel, A. \& de Marco, A. Comparative analysis of prote in aggregates by blue native electrophoresis and subsequent sodium dodecyl sulfate-polyacrylamide gel electrophoresis in a three-dimensional geometry gel. Proteomics, 5(8) (2005), 2002-2009.

[30] Schrodel, A. \& de Marco, A. Characterization of the aggregates formed during recombinant protein expression in bacteria. BMC Biochem., 6:10 (2005).

[31] Wang, W. Protein aggregation and its inhibition in biopharmaceutics. Int J Pharm, 289(1-2) (2005), 1-30.

[32] Alonso, L., Garcia-Alai, M., Smal, C., Centeno, J., Iacono, R., Castano, E., Gualfetti, P. \& de Prat-Gay, G. The HPV16 E7 viral oncoprotein self-assembles into defined sph erical oligomers. Biochemistry., 43(12) (2004), 3310-3317. 
[33] Melnick, A. \& Licht, J. D. Deconstructing a disease: RARalpha, its fusion partners, and their roles in the pathogenesis of acute promyelocytic leukemia. Blood, 93(10) (1999), 3167-215.

[34] Calloni, G., Zoffoli, S., Stefani, M., Dobson, C. M. \& Chiti, F. Investigating the effects of mutations on protein aggregation in the cell. J Biol Chem, 280(11) (2005), 10607-13.

[35] Patro, S. Y. \& Przybycien, T. M. Simulations of kinetically irreversible protein aggregate structure. Biophys J, 66(5) (1994), 1274-89. 
Figulaffer
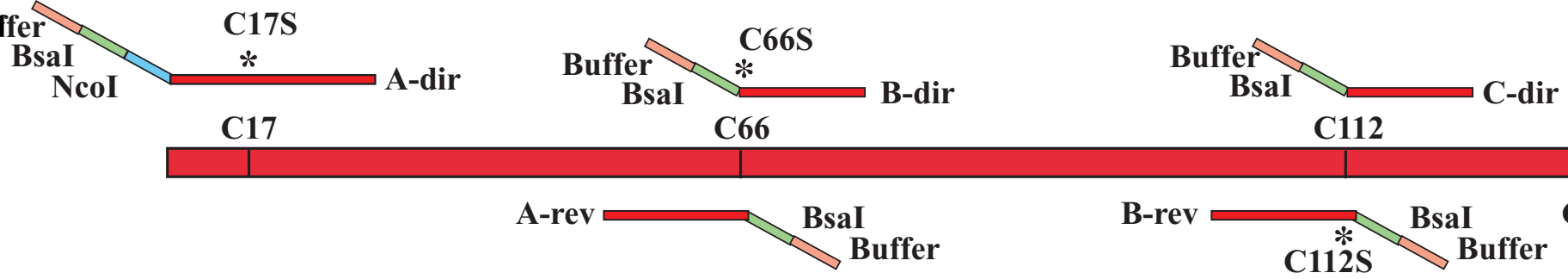

C144

(I) $\downarrow \begin{gathered}\text { PCR amplification } \\ \text { B-dir + B-rev }\end{gathered}$

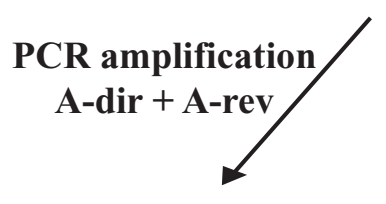

B-rev
PCR amplification
B-dir + B-rev
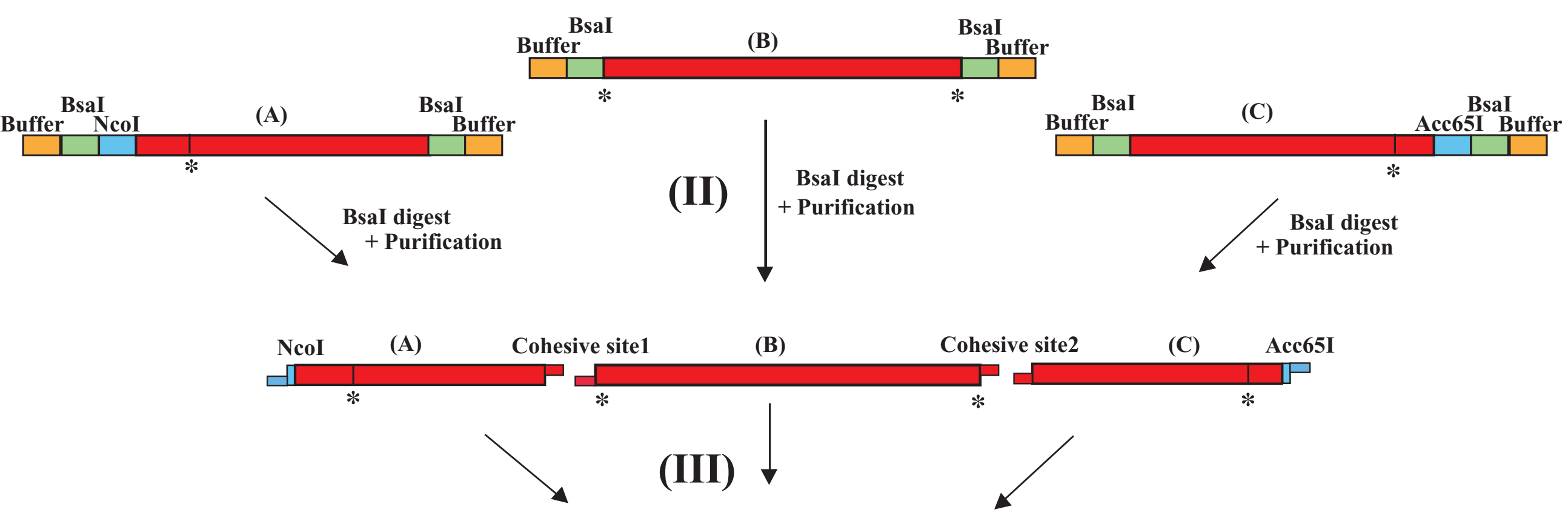

Triple ligation into NcoI/Acc65I cut expression vector

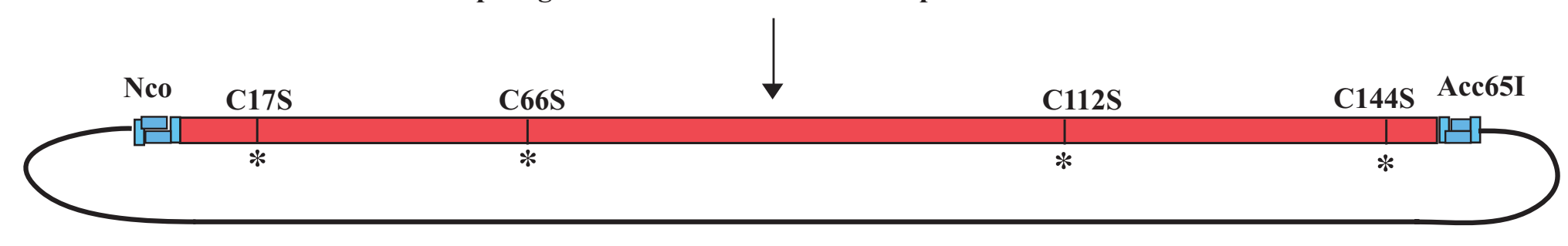


A-dir

Buffer-BSaI-NCOI-MESKDASTSATSIDOLSKTFNL> .

HPV11-E6 :

$1-M E S K D A S T S A T$

Buffer-BsaI-ASCLELQGKINQ $<$ NFPFAACAS-BsaI-Buffer

\section{C-dir}

Buffer-BsaI SEIEKLKHILG>

81-NYAAYAPTVEEETNEDILKVLIRCYLCHKPLCE IEKLKH ILGKARF IKLNNQWKGRCLHCWTTCMEDLLP-150 $\triangleleft$ CYLCHKPLSE-BsaI-Buffer B-rev

\&RCLHCWTTSMEDLLP-stop-Acc65I-BsaI-Buffer C-rev

$\mathbf{B}$

A-dir :

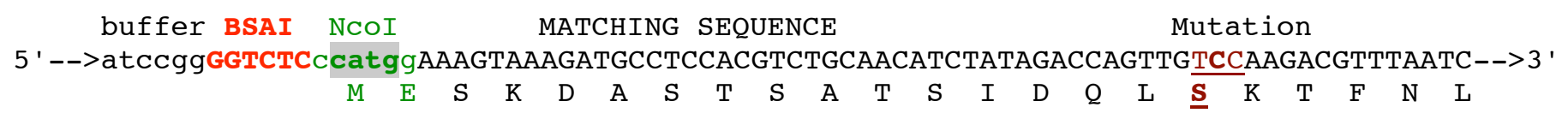

A-rev : MATCHING cohesive1 BSAI buffer

3 '<--GAAAGGGAAACGTCGCACAcggatCTCTGGggcCta<--5 '

$$
\begin{array}{llllllll}
N & F & P & F & A & A & C & A
\end{array}
$$

B-dir: buffer BSAI cohesive1 MATCHING 5 ' -->atccggGGTCTCtgCCtCTTGCTTAGAACTGCAAGGGAAAATTAACC-->3 '

$$
\begin{array}{lllllllllllll}
A & \underline{\mathbf{S}} & \mathrm{C} & \mathrm{L} & \mathrm{E} & \mathrm{L} & \mathrm{Q} & \mathrm{G} & \mathrm{K} & \mathrm{I} & \mathrm{N} & \mathrm{Q}
\end{array}
$$

B-rev :

MATCHING cohesive2 BSAI buffer

3 '<--CAATGGACACAGTGTTCGGCAACagcctCTCTGGggccta<--5 '

$$
\begin{array}{lllllllllll}
C & Y & L & C & H & K & P & L & \underline{\mathbf{S}} & E
\end{array}
$$

C-dir: buffer BSAI cohesive2 MATCHING

5 ' -->atccggGGTCTCctcggAAATAGAAAAACTAAAGCACATATTGGG-->3 '

$$
\begin{array}{llllllllllll}
\underline{\mathbf{S}} & \mathrm{E} & \mathrm{I} & \mathrm{E} & \mathrm{K} & \mathrm{L} & \mathrm{K} & \mathrm{H} & \mathrm{I} & \mathrm{L} & \mathrm{G}
\end{array}
$$

C-rev :

$$
\text { MATCHING ACC65I BSAI buffer }
$$

3 '<--GCAACGAATGTGACGACCTGTTGTAGGTACCTTCTGAACAATGGGATTCcatggCTCTGGggcCta<--5 '

$$
\begin{array}{lllllllllllllllll}
R & C & L & H & C & W & T & T & \underline{\mathbf{S}} & M & E & D & L & L & P & \text { Stop }
\end{array}
$$




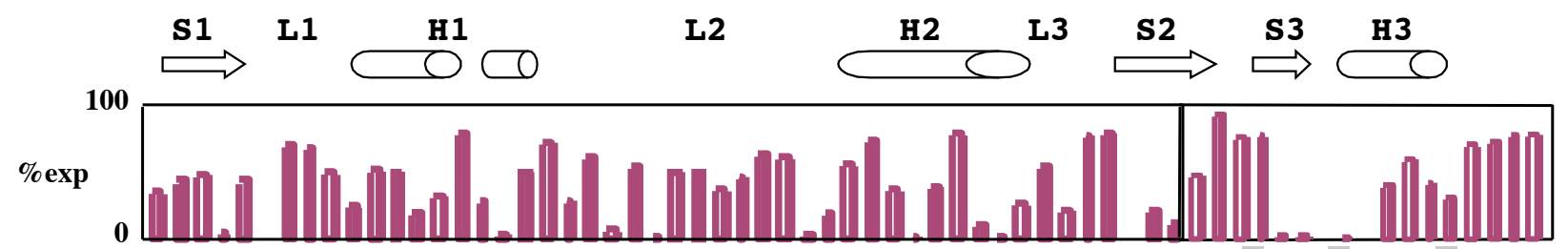

HPV05nt MAEGAEHQQKLTEKDKAELPLSIR. . DLAEALGIPVIDCLIPCNFCGNFLNYLEACEFDYKRLSLIWKDYCVFACCRVCCGATATYEFNQFY

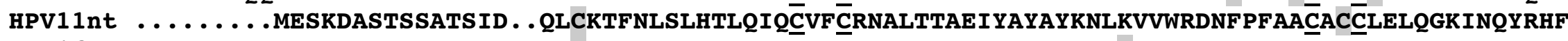
HPV16Rnt .........MFQDPQERPRKLP. . QLCTELQTTIHDI ILECVYCKQQLLRREVYDFAFRDLCIVYRDGNPYAVCDKCLKFYSKISEYRHY

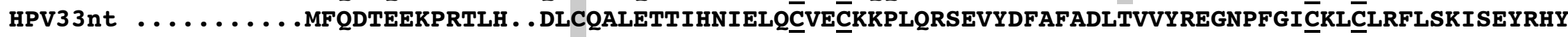

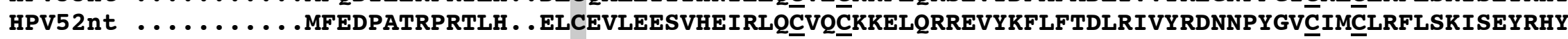
HPV58nt . . . . . MFQDAEEKPRTLH . .DLCQALETSVHEIELKCVECKKTLQRSEVYDFVFADLRIVYRDGNPFAVCKVCLRLLSKISEYRHY

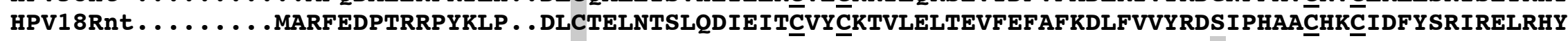
HPV45nt .......MARFDDPKQRPYKLP. .DLCTELNTSLQDVSIACVYCKKATLERTEVYQFAFKDLFIVYRDCIAYAACGKCIDFYSRIRELRYY

HPV05ct. . . . . . . . E ETVLGRDIELASGLS IFDIDIRCQTCLAFLDI IEKLDCCGRGLPFHKVRNAWKGICRQCKHFYHDW HPV11ct $\ldots \ldots \ldots \ldots \ldots \ldots$ NYAAYAPTVEEETNEDILKVLIRCYLCHKPLCEIEKLKHILGKARF IKLNNQWKGRCLHCWTTCMEDLLP

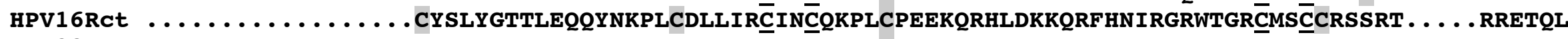
HPV3 $3 \mathrm{ct} \quad \ldots \ldots \ldots \ldots \ldots \ldots$ NYSVYGNTLEQTVKKPLNEILIRCIICQRPLCPQEKKRHVDLNKRFHNISGRWAGRCAACWR . .SR . . . . RRETAL HPV52ct $\ldots \ldots \ldots \ldots \ldots \ldots$ QYSLYGKTLEERVKKPLSEITIRCIICQTPLCPEEKERHVNANKRFHNIMGRWTGRCSECWR..P.....RPVTQV

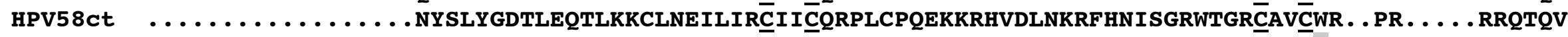
HPV18RCt $\ldots \ldots \ldots \ldots \ldots \ldots$ SDSVYGDTLEKLTNTGLYNLLIRCLRCOKPLNPAEKLRHLNEKRRFHNIAGHYRGOCHSCCNRAROERLORRRETOV

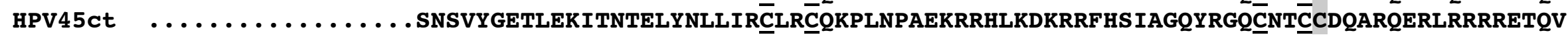



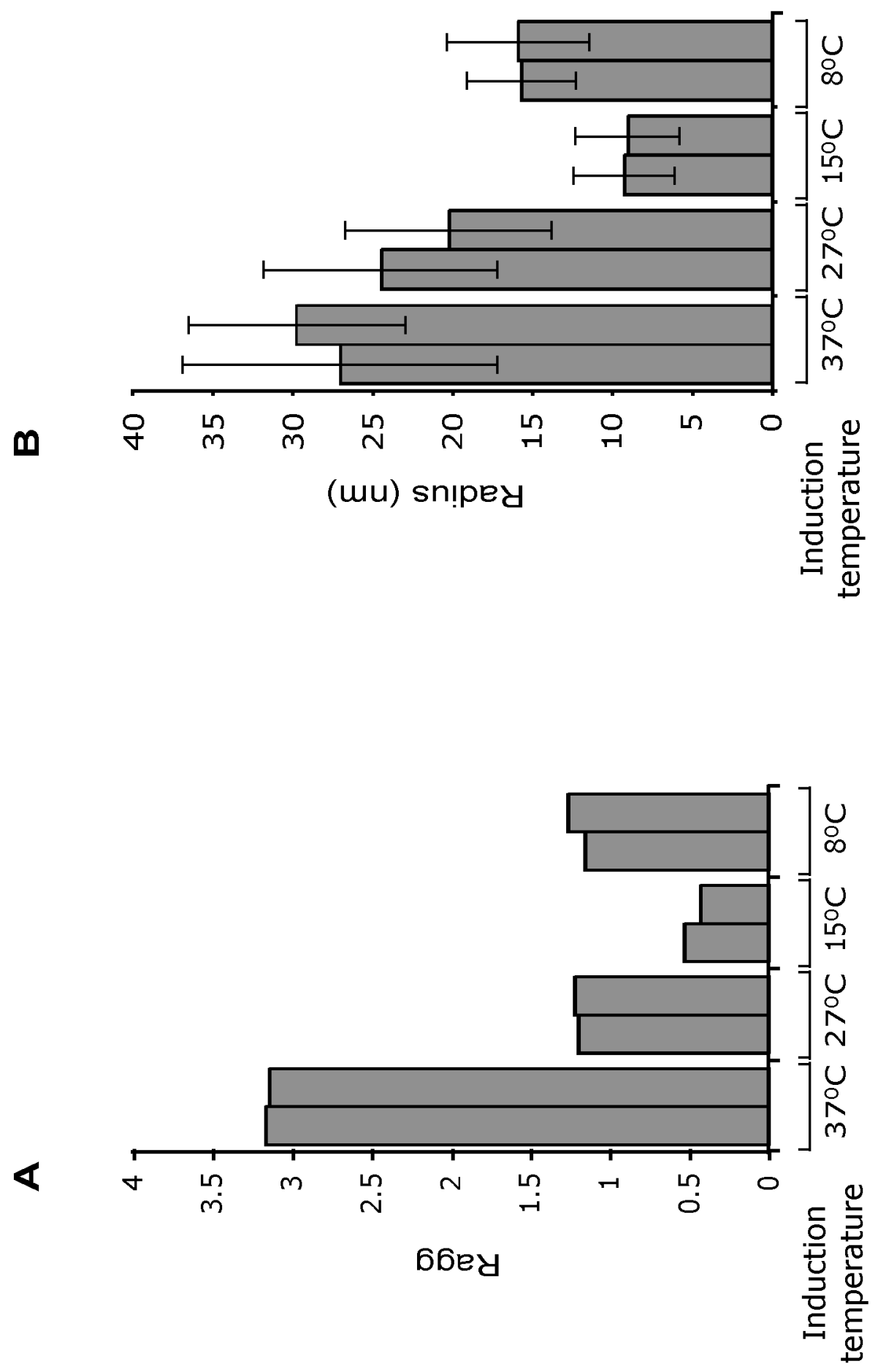


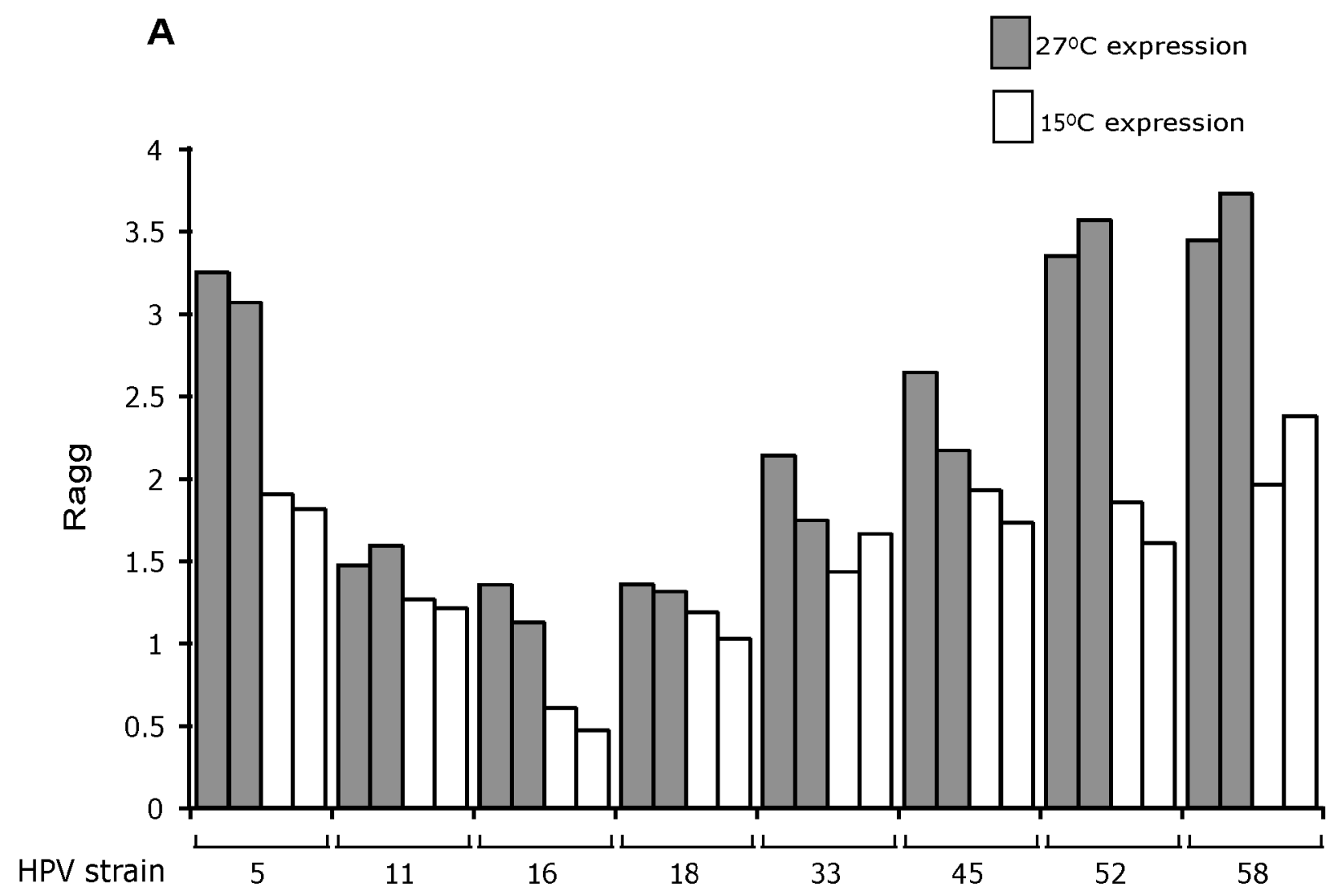

B

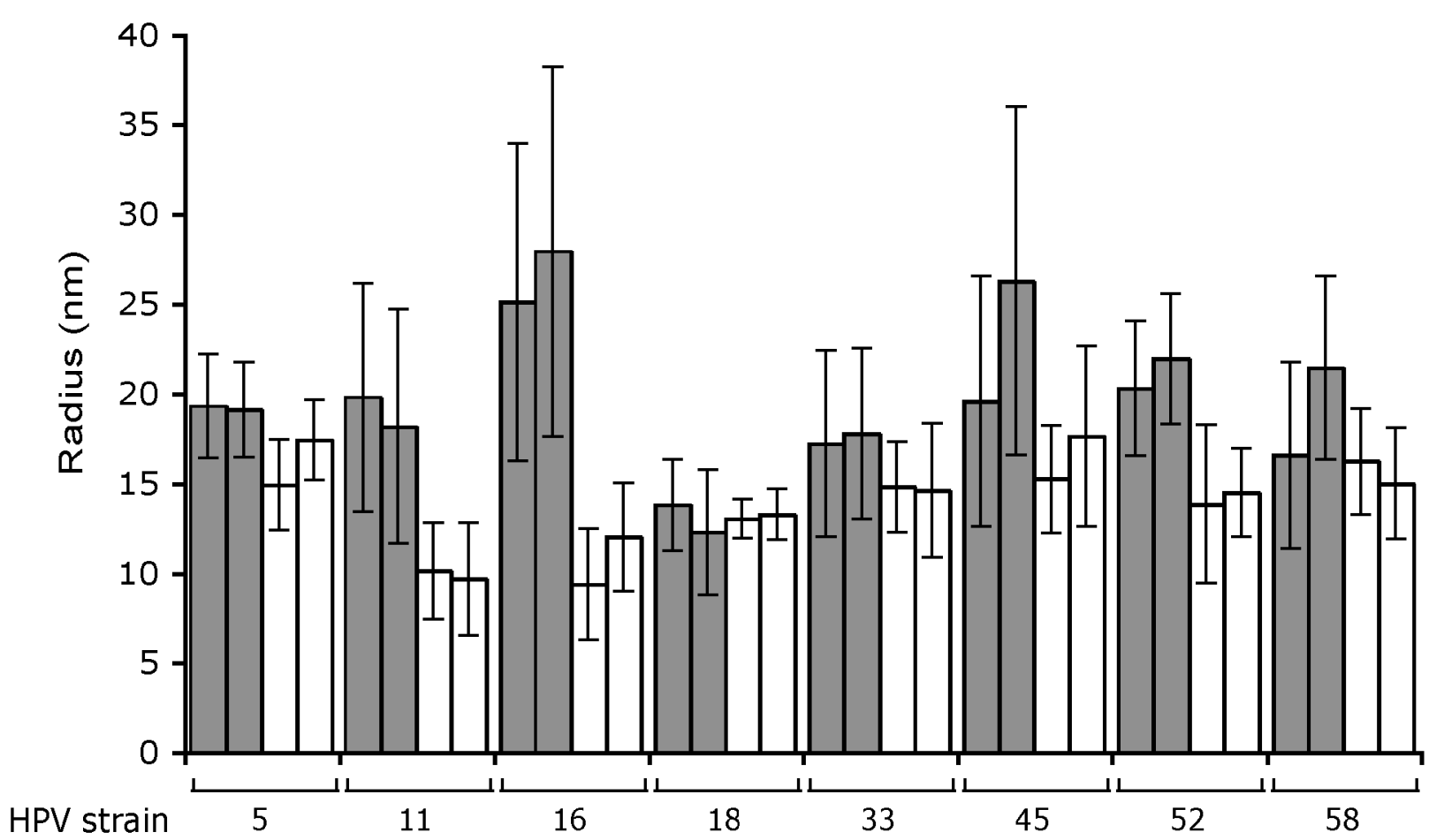


Click here to download high resolution image

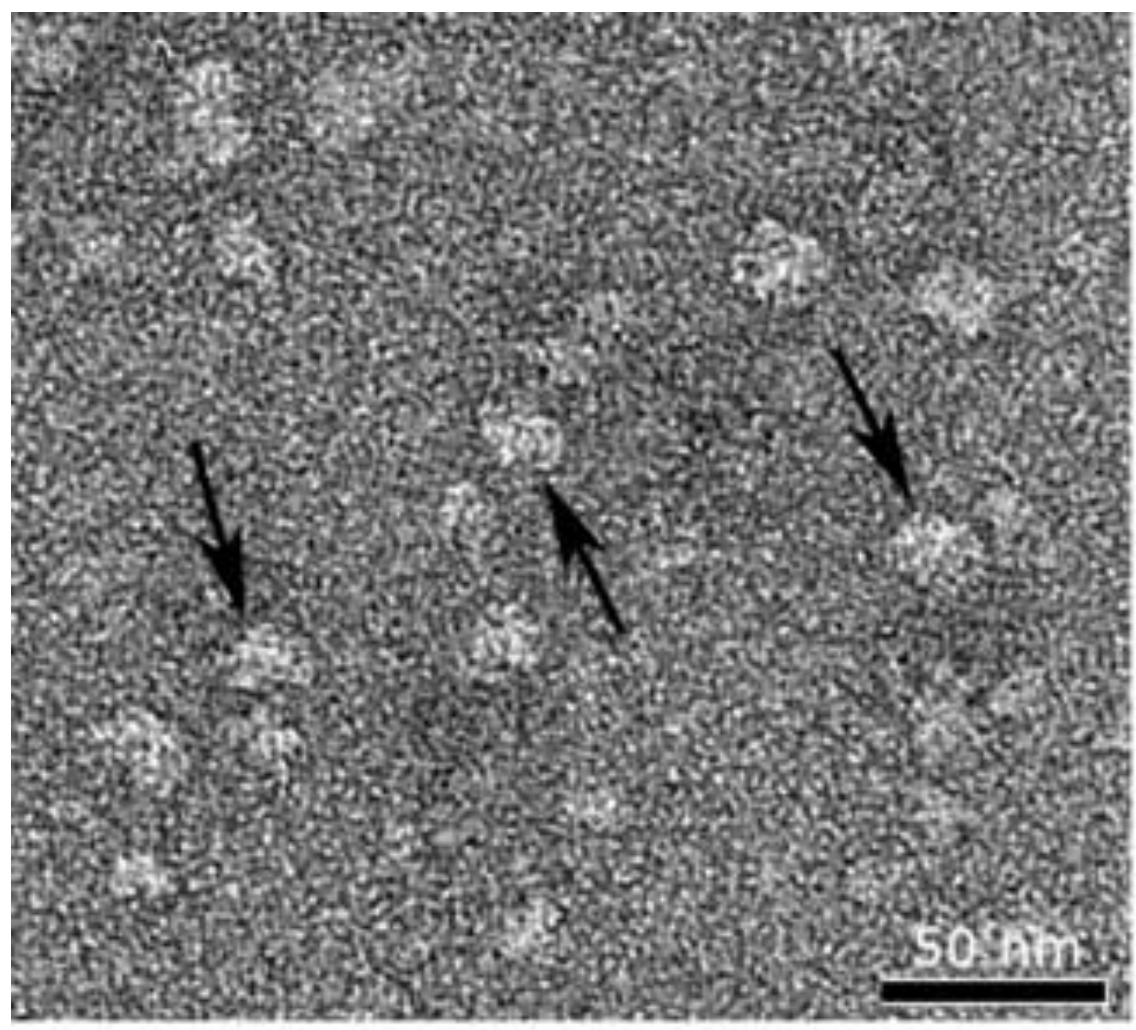



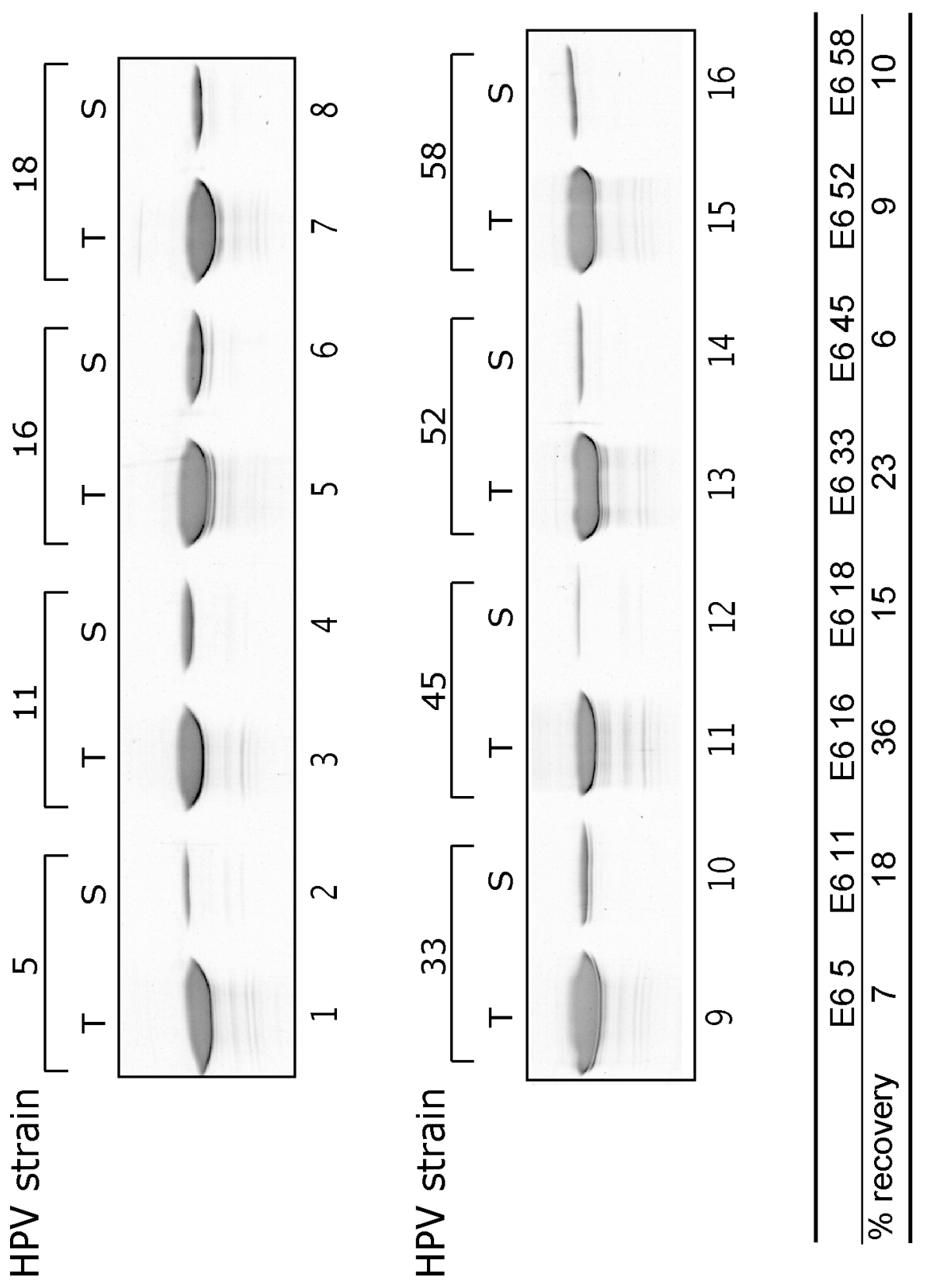


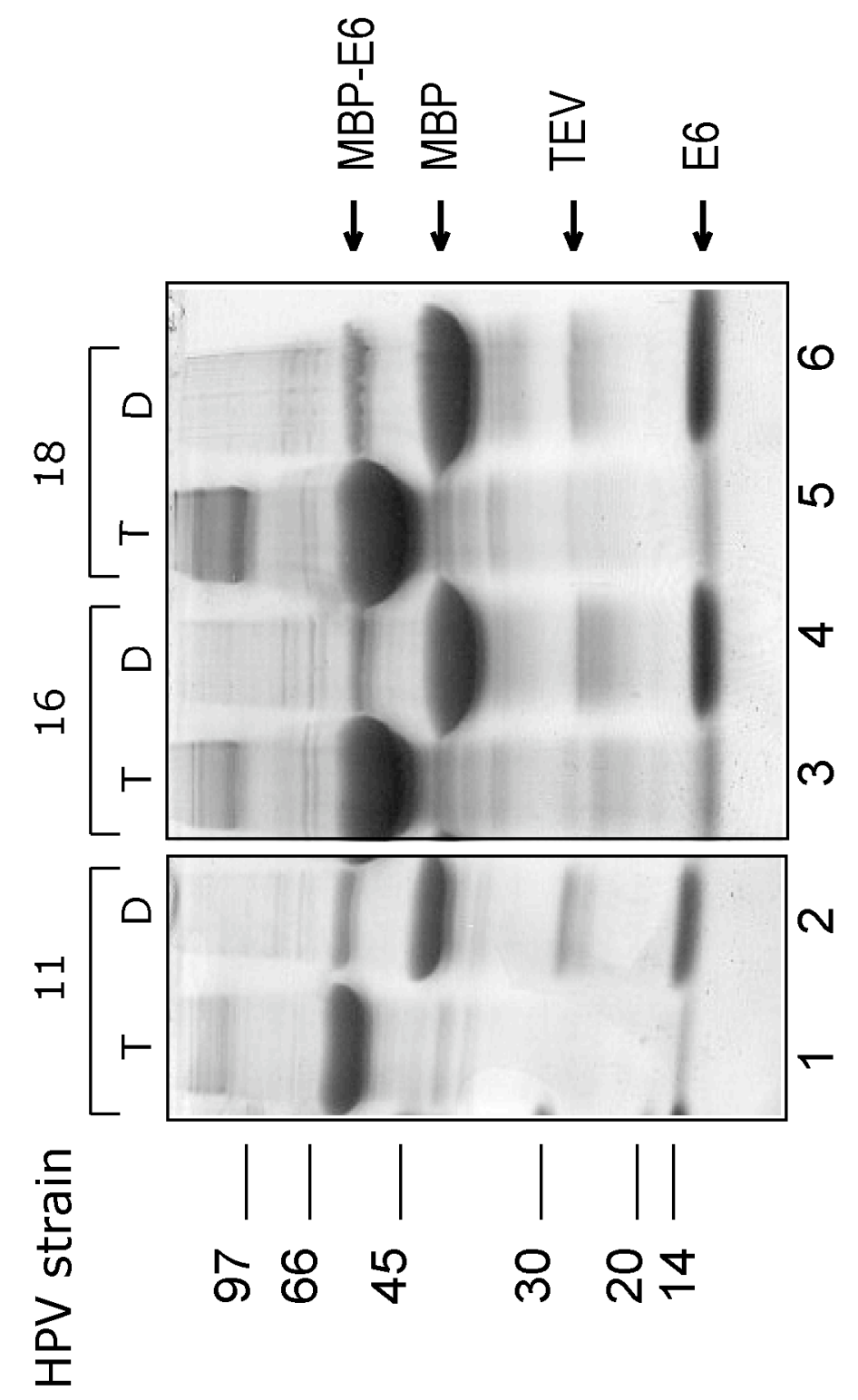




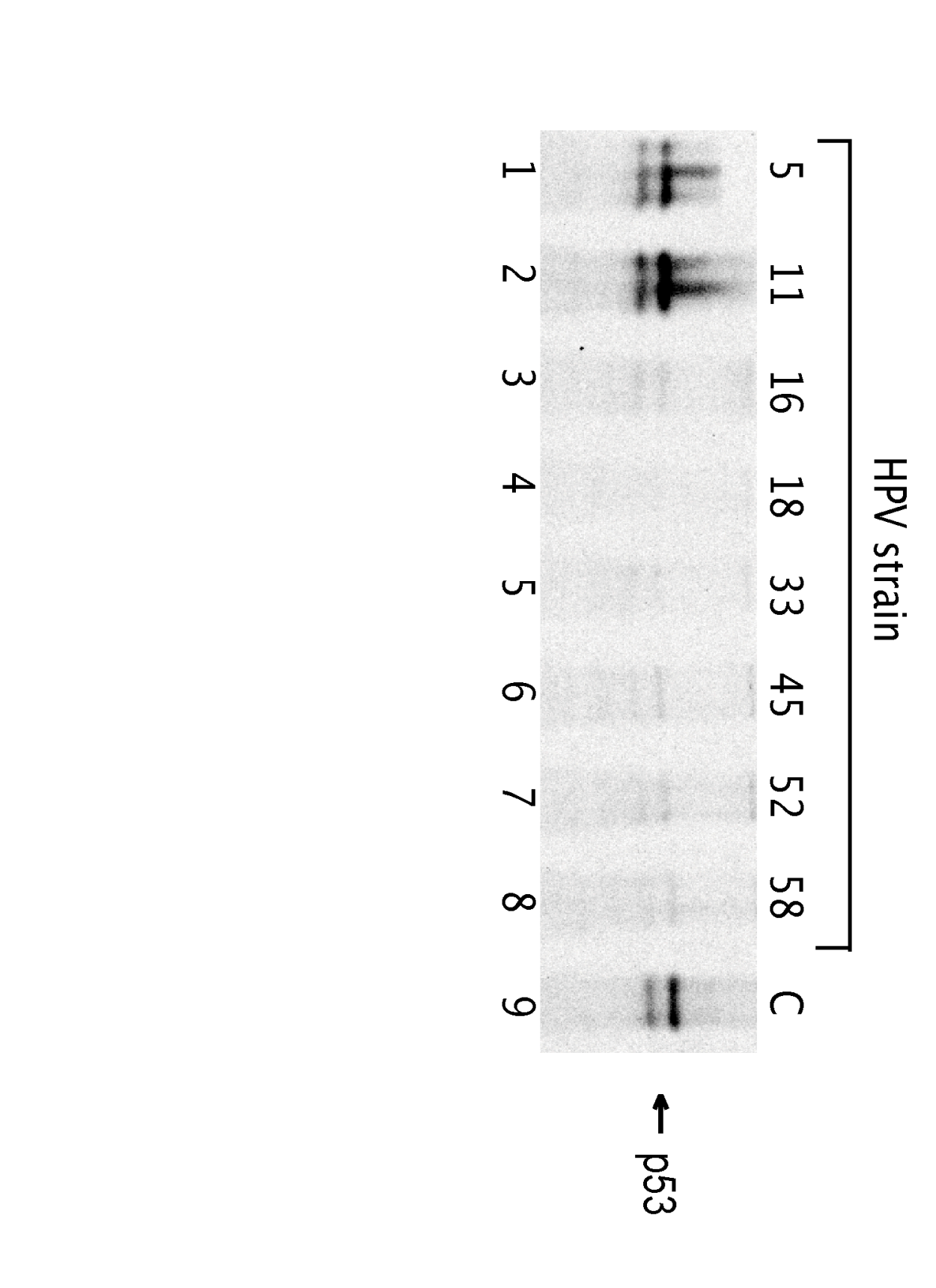

Figure9

\section{Figureg}

$$
\text { (1) }
$$$$
\text { . }
$$
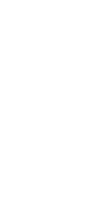


\begin{tabular}{cc}
\hline $\begin{array}{c}\text { MBP-E6 } \\
\text { samples }\end{array}$ & $\begin{array}{c}\mathrm{Zn}^{2+} \text { : protein } \\
\text { stoichiometry }\end{array}$ \\
\hline $11 \mathrm{~T}$ & $1.95 \pm 0.05$ \\
$11 \mathrm{~S}$ & $1.93 \pm 0.10$ \\
$16 \mathrm{~T}$ & $1.79 \pm 0.07$ \\
$16 \mathrm{~S}$ & $1.97 \pm 0.23$ \\
$18 \mathrm{~T}$ & $1.81 \pm 0.06$ \\
$18 \mathrm{~S}$ & $1.85 \pm 0.08$ \\
\hline
\end{tabular}

